\title{
Bird diversity and waterbird habitat preferences in relation to wetland restoration at Dianchi Lake, south-west China
}

\author{
Kang Luo ${ }^{1,2,3,4}$, Zhaolu Wu ${ }^{2 *}$ (D) Haotian Bai ${ }^{2}$ and Zijiang Wang ${ }^{2}$
}

\begin{abstract}
Background: Restoration projects have been implemented worldwide to mitigate the adverse effects of the loss and degradation of wetland habitats. Much research has been carried out on the impacts on birds of wetland restoration and management projects in China. Studies have mainly investigated central or coastal wetlands, while inland wetlands in remote areas have been much less studied. We focused on examining the response of wild birds to wetland restoration in Dianchi Lake, south-west China.

Methods: The line transect method was performed at 26 sampling plots. Three of these were in the city, and to acquire all wild bird data 23 plots were located every 2-8 km along the shore of Dianchi Lake, between December 2011 and November 2013. We collected all related bird records by searching the available literature, articles, newspapers and records of birdwatchers to compare species variation before and after implementation of wetland restoration. To measure the relationships between waterbird assemblages and habitat structures, we used canonical correspondence analysis (CCA) to pair the main matrix of bird assemblages with a second matrix of habitat variables.

Results: We recorded 182 bird species belonging to 51 families and 17 orders. Of the species, 42 were new records for Kunming City and 20 were new records for Yunnan Province. Ten waterbird species were found to have disappeared from the shore of Dianchi Lake. CCA results indicated that waterbirds could be divided into four categories based on their habitat preference: synanthropic (wintering gulls), special habitat (shorebirds), semi-natural (wintering coots and ducks) and disturbance-tolerant (resident) species.
\end{abstract}

Conclusions: Our study is the first to consider the entire wild bird community throughout the year and discuss the species variation before and after wetland restoration projects launched for Dianchi Lake. Distinct habitat requirements of different waterbird groups were detected in our study, suggesting different types of restoration and management should be implemented.

Keywords: Dianchi Lake, Waterbird, Habitat utilization, Shorebird, Conservation

\section{Background}

Wetlands harbor highly diverse biological communities and provide extensive ecosystem services such as water purification, flood abatement and climate regulation (Zedler and Kercher 2005). However, they are frequently degraded and destroyed. It was estimated that over 50\% of total wetland surface was lost during the last century

\footnotetext{
*Correspondence: zlwu@ynu.edu.cn

${ }^{2}$ Institute of Ecology and Geobotany, Yunnan University,

Kunming 650091, China

Full list of author information is available at the end of the article
}

(Mitsch and Gosselink 2007). Consequently, declines in wetland-dependent species have been some of the greatest recorded (Sievers et al. 2018), and wetland birds in particular are sensitive indicators of wetland conditions. Wetlands in urban settings fulfill additional environmental and social needs, which include storm-water retention of runoff from impervious surfaces, as well as removing pollutants and waste from water. Urban wetlands also provide extended recreational opportunities and visual aesthetics. The economic benefits include potentially reducing infrastructure costs, due to their ability

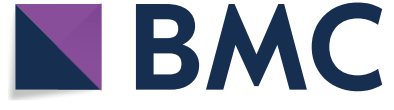

(c) The Author(s) 2019. This article is distributed under the terms of the Creative Commons Attribution 4.0 International License (http://creativecommons.org/licenses/by/4.0/), which permits unrestricted use, distribution, and reproduction in any medium, provided you give appropriate credit to the original author(s) and the source, provide a link to the Creative Commons license, and indicate if changes were made. The Creative Commons Public Domain Dedication waiver (http://creativecommons.org/ publicdomain/zero/1.0/) applies to the data made available in this article, unless otherwise stated. 
to act as storm-water retention areas (Asomani-Boateng 2019). Unlike rural wetlands, urban wetlands are subject to urban development pressures, resulting in profound and extensive damage, loss, and degradation (Zedler and Leach 1998; Ehrenfeld 2000). The effects of urbanisation on bird diversity may be mitigated by the presence of wetlands, which may provide enhanced habitat and increase resource availability. Nevertheless, urbanization is one of the main driving factors in the degradation of natural wetlands (Russi et al. 2013). Wetland restoration projects are believed to be beneficial to storm water treatment or public amenities, but are also expected to compensate for bird habitat loss as natural wetlands decline (Zedler 2000; Mao et al. 2019). Restoration projects have been implemented worldwide to mitigate adverse effects resulting from the loss and degradation of wetland habitats (Pethick 2002; Nakamura et al. 2006). It is important, therefore, to understand the habitat requirements of birds, and to assess the suitability of habitats for birds, when restoring wetlands (Ma et al. 2010; Terörde and Turpie 2013).

In China, there has been serious wetland degradation due to urbanization and other anthropogenic threats during the last six decades. Fortunately, large numbers of wetland reserves have been established, and a wide range of management and restoration projects have been implemented in both inland and coastal areas since 1980 (Xu et al. 1999; An et al. 2007). Nevertheless, most useful research on the impacts of wetland restoration or management projects on birds in wetland reserves has considered affluent and developed areas, namely eastern or coastal China (such as Chongming Island, Ma et al. 2002; Yellow River Delta, Li et al. 2011 and Hua et al. 2012; Dongting River, Yuan et al. 2014; Mai Po, Wei et al. 2018). While coastal wetlands have been identified as important habitat for more than 230 species of waterbirds (Cao and Fox 2009), inland wetlands located in remote areas are much less studied (Wang et al. 2018). Many of these do not even appear in the Ramsar List of Wetlands of International Importance.

Wetlands and lakes in Yunnan Plateau, south-west China, are important habitats for waterbirds (Chen 1998; Cui et al. 2014). Most studies have a seasonal focus on wintering waterbirds in Lashihai (Quan et al. 2002), Napahai and Bitahai wetlands (Han et al. 2009; Li and Sun 2014), Luguhu Lake (Li and Yang 2015), Qionghai Lake (Hu et al. 2015) and Dianchi Lake (Wang et al. 2006; Wu et al. 2008, 2009; Han et al. 2012). Few studies have documented diversity of all wild birds throughout the year (Han et al. 2014).

Dianchi Lake, a vital shallow lake next to Kunming City, the political and cultural center of Yunnan Province, has been greatly affected by human disturbance and has undergone severe degradation since the $1980 \mathrm{~s}$. The implementation of an ambitious large-scale ecological restoration project, the "Kunming Urban Master Plan (2008-2020)", began along the shore of Dianchi Lake in 2008. Most researches about Dian Lake focus on the water quality recovery, while there is little information about how birds are responding to the restoration of Dianchi Lake wetlands (but see Wang et al. 2016). The aims of the present study were to: (1) record the entire wild bird composition; (2) identify differences in species occurrences between historical and current data; and (3) analyze waterbird habitat preference with respect to wetland restoration. Finally, we discuss waterbird response, in a general sense, to wetland restoration under conditions of urbanization.

\section{Methods}

\section{Study area}

Dianchi Lake $\left(24^{\circ} 40^{\prime}-25^{\circ} 20^{\prime} \mathrm{N}, 102^{\circ} 36^{\prime}-102^{\circ} 47^{\prime} \mathrm{E}\right)$ is an ancient tectonic lake located in the Yunnan-Guizhou Plateau in the Yangtze River Basin (Fig. 1a, b; Xiang 2014; Ma and Wang 2015). With an area of $308.6 \mathrm{~km}^{2}$, it is the sixth largest freshwater lake in China and the largest on the plateau. It is separated into two parts by a semiartificial dam: the northern part, Caohai, has a water area of $10.7 \mathrm{~km}^{2}$ and a mean water depth of $2.5 \mathrm{~m}$; the southern part, Waihai, has a water area of $297.9 \mathrm{~km}^{2}$ and a mean water depth of $4.3 \mathrm{~m}$. The regional climate is a subtropical humid monsoon type, with a mean temperature of $14.4{ }^{\circ} \mathrm{C}$, mean annual precipitation of $1036.1 \mathrm{~mm}$ and 227 frost-free days per year (Wang and Dou 1998). More than 20 main streams comprise the Dianchi Lake watershed, and the lake's stable water level of $1886.9 \mathrm{~m}$ above sea level is maintained by an artificial floodgate in the only natural outlet south-west of Waihai. The lake is nearly semicircular: its length is $40.4 \mathrm{~km}$ and it has a mean width of $7.0 \mathrm{~km}$. The shoreline is $150 \mathrm{~km}$ (Yang et al. 2010) in extent. Located in the southern suburbs of Kunming City, Dianchi Lake plays important roles in industrial and agricultural water supply, water storage regulation, flood control and tourism.

It was known for its crystal-clear water and was once dubbed "the pearl of the Yunnan-Guizhou Plateau". However, the lakeside was over-reclaimed in the 1970s and the water has become heavily eutrophic. The ability of the lake to self-purify has not been able to keep up with the massive discharge of municipal and industrial sewage into the water. Along with Taihu and Chaohu lakes, Dianchi is listed as one of the three most polluted lakes in China (Liu and Qiu 2007). 


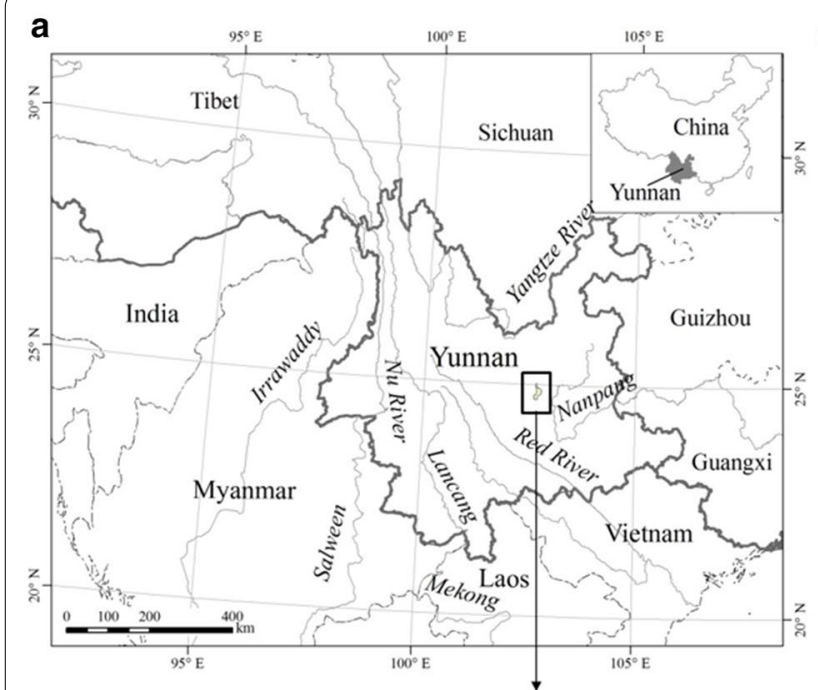

C

b
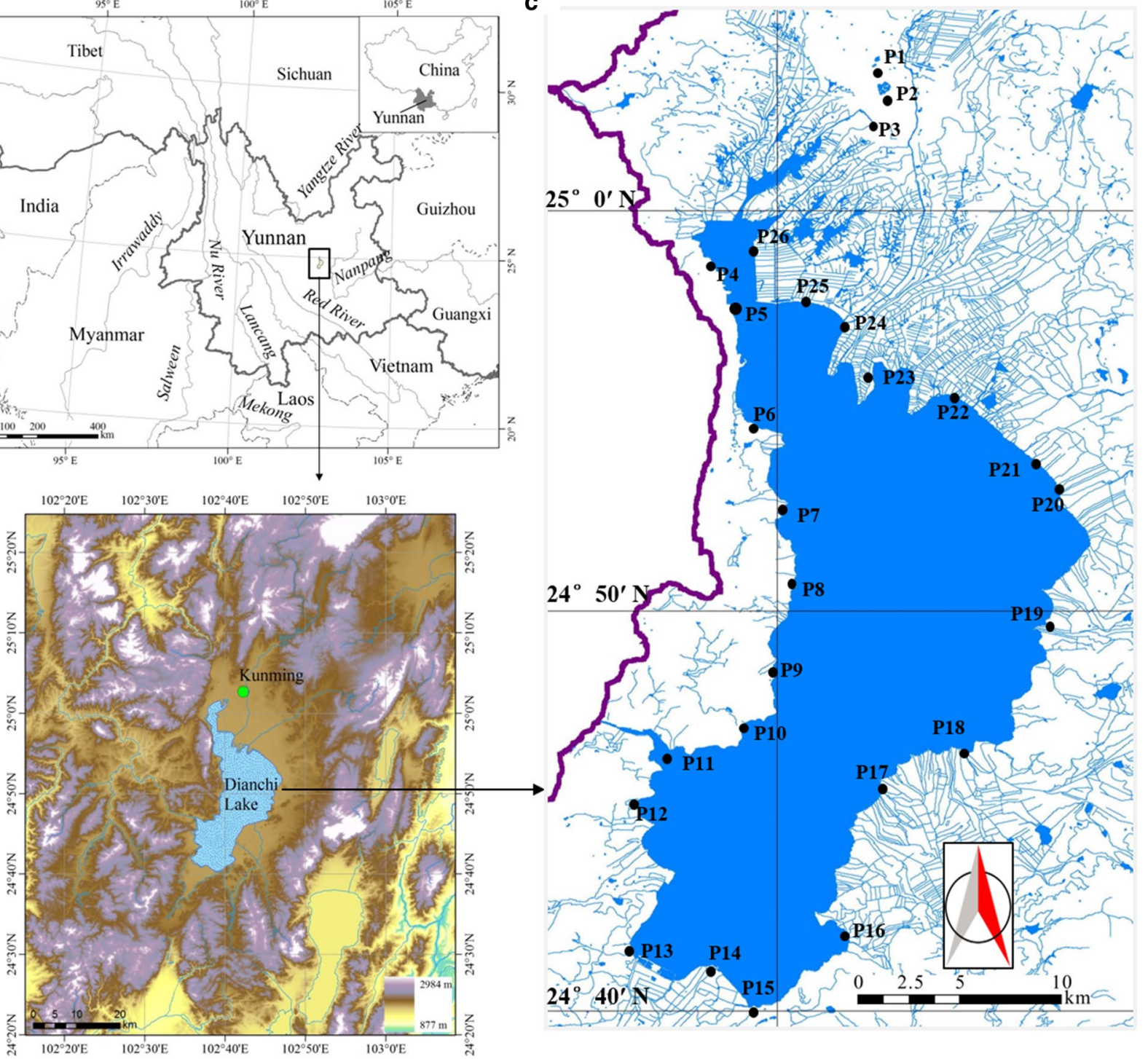

Fig. 1 Location of the Dian Lake $(\mathbf{a}, \mathbf{b})$ and the sampling sites along the Dianchi Lake (c)

In 1988, Kunming Municipality enacted the Dianchi Protection Regulations to carry out a comprehensive ecological restoration plan. An ambitious large-scale ecological restoration project, the "Kunming urban master plan (2008-2020)", has been implemented along the lakeside of Dianchi Lake since 2008. This is an attempt to build a green wetland belt around the lakeside, reconstructed from farmland, fishponds and residential areas, and aims to recover the wetland ecosystem function. Reed, cattail, water hyacinth, duckweed and trees were planted in the restored artificial wetlands, as these are the most conspicuous landscapes in the lakeside ecological belt.

\section{Sampling plots}

We surveyed birds at 26 sampling plots: 3 plots in Kunming City and 23 plots every 2-8 km along Dianchi lakeside (Fig. 1c). The plots covered multiple types of environmental gradients (urban and suburban areas, low and high human density, semi-natural wild areas and areas under construction), as well as habitats (forested, grassy, cultivated and built areas, open water, and mosaics of land and water). Land covers of sampling plots were classified into 12 types based on Google Earth images and field observation (Table 1). We obtained the satellite images from Google Earth for each plot and measured 
the amount of obvious land cover. This included areas of water, mud flood (MF), building area (BA), small pond $(\mathrm{SP})$, cultivated land (CL) and wasteland (WL), as identified by Arcgis. We estimated the percentage of open water area (OA) and macrophyte cover (MC) of the water area during field surveys in April 2013. We also estimated plant cover variables: forest cover [Dry forest cover (DF) and wetland forest cover (WF)] was estimated in five randomly selected quadrats $(20 \mathrm{~m} \times 20 \mathrm{~m})$ along each transect. Within each forest cover estimation quadrat, we randomly selected four quadrats $(5 \mathrm{~m} \times 5 \mathrm{~m})$ to estimate shrub (SB), high grassland (HG) and low grassland (LG) coverage. A matrix of habitat variables consisting of the coverage percentages of 12 types of land cover was produced for further analysis (see details in Additional file 1: Table S1).

\section{Bird data \\ Bird surveys}

Field bird surveys were carried out continuously for 24 months from December 2011 to November 2013 to obtain basic bird composition data. Surveys were conducted in the mid-part or late in each month for 3-4 days from 08:00-12:00 to 13:30-18:30 each day. The transect method was used to survey wild birds. As the lakeshore micro-habitats usually included open areas and areas densely filled with plants, three types of transect were used: type 1 for open habitat $(300 \mathrm{~m} \times 200 \mathrm{~m})$, type 2 for dense habitat $(300 \mathrm{~m} \times 50 \mathrm{~m})$ and type 3 for habitat containing a dense area next to an open area $(300 \mathrm{~m} \times 125 \mathrm{~m})$. Between one and three transects were carried out in each plot according to plot size (details in Additional file 1: Table S1). It usually took $15 \mathrm{~min}$ to count the birds in each transect (Ntongani and Andrew 2013). All birds heard, seen in or hovering over the plots were counted. Birds that flew over the plots quickly (usually taking less than $10 \mathrm{~s}$ ) were not recorded. All individuals were counted, and group-counting was used in the case of large flocks (more than 500 individuals) (Bibby et al. 2000; Yuan et al. 2014). Birds were observed using telescopes (Celestron 20-60 $\times 80$ monocular and Sharks $8 \times 42$ binocular) and photographed with digital cameras (Canon 650D; EF $400 \mathrm{~mm} \mathrm{f} / 4-5.6 \mathrm{~L}$ IS USM). Bird species were identified according to MacKinnon et al. 2000 and the IOC Checklist (v 4.4) (Gill and Donsker 2014). We used the maximum number of individuals counted in a single month as the species abundance for each species.

Information on bird breeding divisions and migration status was obtained from Yang and Yang (2004) and Zhao (2001). Birds were classified into waterbird (two ecological types: Grallatore and Natatores) and non-waterbird (four ecological types: Passeres, Terrestores, Raptors and Scansores) (Zhao 2001; Zheng 2012). Waterbirds were further divided into 7 sub-groups: gulls (SG1), wintering coots and ducks (SG2), shorebirds (SG3), egrets (SG4), breeding rails (SG5, dominated by the resident species Gallinula chloropus), grebes (SG6, dominated by the resident species Tachybapus ruficollis) and others (SG7, only containing a total of 6 individuals belonging to 5 species, excluded from further analysis) for further habitat preference analysis (Cardoni et al. 2008; Zhang et al. 2011; Yuan et al. 2014; Wei et al. 2018).

\section{Table 1 Classification and description of microhabitat Land-cover along Dianchi Lake}

\begin{tabular}{|c|c|c|}
\hline First class & Second class (abbreviation) & Description (all calculated as \%) \\
\hline \multirow[t]{2}{*}{ Water area } & Open water area $(\mathrm{OA})$ & Covered without macrophytes \\
\hline & Macrophyte cover (MC) & Covered with the macrophytes, dominant by Eichhornia crassipes and Pistia stratiotes \\
\hline \multirow[t]{10}{*}{ Land area } & Building area (BA) & Covered by obviously anthropogenic buildings, dams, roads, trails, etc. \\
\hline & Small pond cover (SP) & Ponds located outside the bank, usually formed by the derelict fish-ponds, water depth>10 cm \\
\hline & Mud flood area (MF) & $\begin{array}{l}\text { Bare land in wet condition, water depth } \leq 10 \mathrm{~cm} \text {, the largest one was occasionally formed by an restoration } \\
\text { engineer for water purification with the mud relocating to bank side }\end{array}$ \\
\hline & Low grassland cover (LG) & $\begin{array}{l}\text { Short grass species coverage such as Alternanthera philoxeroides, Phragmites australis, Acorus calamus and } \\
\text { Zizania latifolia. Generrally, in wet condition and height }<2 \mathrm{~m}\end{array}$ \\
\hline & High grassland cover $(\mathrm{HG})$ & $\begin{array}{l}\text { High grass species coverage such as Saccharum spontaneum and Pennisetum purpureum, in dry condition } \\
\text { and height } \geq 2 \mathrm{~m}\end{array}$ \\
\hline & Dry forest cover (DF) & $\begin{array}{l}\text { Forest in dry condition, generally in the well-manage parks refer to the nursery gardens/orchards/forest } \\
\text { remnants. }\end{array}$ \\
\hline & Wetland forest cover (WF) & Forest in wet condition, generally dominant by the introduced species Taxodium hybrid 'zhongshanshan' \\
\hline & Cultivated land cover $(\mathrm{CL})$ & Active farmlands generally included rice paddies/vegetable lands/cornfields \\
\hline & Waste lands cover (WL) & $\begin{array}{l}\text { Inactive farmlands, generally dry with much weed species coverage such as Artemisia argyi and Bidens } \\
\text { pilosa }\end{array}$ \\
\hline & Shrub cover (SB) & Shrub coverage, dominant by Pyracantha crenatoserrata and Dichotomanthus tristaniaecarpa \\
\hline
\end{tabular}




\section{New bird records and absent species}

In this paper, we define new records of birds in Kunming and Yunnan as species recorded along Dianchi Lake between 2008 and 2016, as the restoration projects mainly began in 2008 .

In addition to our own field observations, new bird records were obtained by searching published papers using "new bird record", "bird", "Yunnan", "Dianchi" and "Kunming" as keywords at CNKI and CQVIP, two databases of Chinese journals, and the Google Scholar for Chinese website. We also checked the references listed in the publications we collected for any potential literature we had overlooked. We also searched all articles and newspapers relating to birds in Dianchi Lake, using Baidu Search. Finally, we communicated with birdwatchers (Yunnan Bird Association) who had investigated Dianchi Lake to record birds. After acquiring the records, we first confirmed that the data from scientific publications were accurate and reliable, and reviewed the few debated records with other researchers. The related records from Baidu Search and birdwatchers were adopted only when robust evidence (e.g. photos) was available. The earliest literature related to Dianchi Lake we could reach was published in 1960 (Kuang 1960), which conducted field surveys during 1958 and 1959. Therefore, we categorized the records obtained from searching data collected during 1958 to 2008 as historical, and those from between 2008 and 2016 as new.

Because there was no reliable and special representative bird checklist for Dianchi Lake before 2008, we compared our current bird records (including our own field observation data and those of others) with the bird checklists of Kunming City and Yunnan Province to produce the new bird record for Kunming (hereafter NKB) and for Yunnan (NYB). We used the appendix of Wang et al. (2015) as the bird checklist of Kunming. As the appendix provided dynamic historical information for some waterbird species that were explicitly recorded along Dianchi Lake, we also detected that some species had vanished from the shore of Dianchi Lake. The bird checklist of Yunnan mainly refers to Yang and Yang (2004).

\section{Data analysis}

To test whether our sampling effort was sufficient to represent the bird species richness of Dianchi Lake, we first performed rarefaction analyses based on a Monte Carlo simulation procedure implemented with EcoSim7.0 (Gotelli and Entsminger 2006).

Canonical correspondence analysis (CCA) was performed to reveal the relationships between waterbird assemblages and habitat variables (Yuan et al. 2014; Wei et al. 2018). In CCA, habitat data were considered as explanatory variables and abundances of waterbirds were taken as response variables. For both the habitat and species data, no data transformation was applied. We used all 12 variables to perform the CCA analysis and produce the CCA bi-plot. We also performed a Pearson two-tailed test to determine the correlation coefficients between different habitat variables. Forward selection procedures were then applied to test the habitat variables with significant influences. Partial CCA was executed to determine the independent influence of each variable; when a significant variable was used as a definitive one, the others were used as covariables. The proportion of explained variation (net effect) was measured by using the ratio of particular canonical eigenvalues to the sum of all eigenvalues in partial CCA procedures (Lososová et al. 2004). We performed a partial CCA and a Monte Carlo permutation test with 999 permutations to evaluate the significance of variables separately. The statistical significance of each species responding to the five major environmental variables was tested by producing $t$-value bi-plots based on the CCA procedure. All the analyses were carried out in CANOCO 4.5 (Lepš and Šmilauer 2003).

\section{Results}

\section{Sampling adequacy and species composition}

The results of sample-based rarefaction curves illustrated the completeness of survey inventories and the sufficiency of sampling efforts, because of their rapid approach to an asymptote (Fig. 2). In total, 25,102 records for birds belonging to 182 species, 51 families and 17 orders were recorded during the 24 continuous months from December 2011 to November 2013. Of these, 67 species were waterbirds and 115 were non-waterbirds. Many of the birds recorded are protected nationally or internationally. Of the 182 species, nine were found to be "second-class protected species" in China and 144 species appeared in the Lists of state-protected terrestrial wildlife with beneficial or important economic or scientific value in China. We found that 74 species were biprotected between China and Japan and 38 species were bi-protected between China and Australia (see details in Additional file 2: Table S2).

The greatest number of registered species were from the order Passeriformes (95 species, accounting for $52.20 \%$ of total registered species), while the Charadriiformes was the order with highest number of records $(14,703$ records, $58.57 \%$ of total records) owing to the dominance of wintering Black-headed Gulls (Chroicocephalus ridibundus) (14,285 records; see details in Additional file 2: Table S2). Of the five different categories related to migration status, residents accounted for the highest number of species, while winter visitors accounted for the largest number of individual records. 


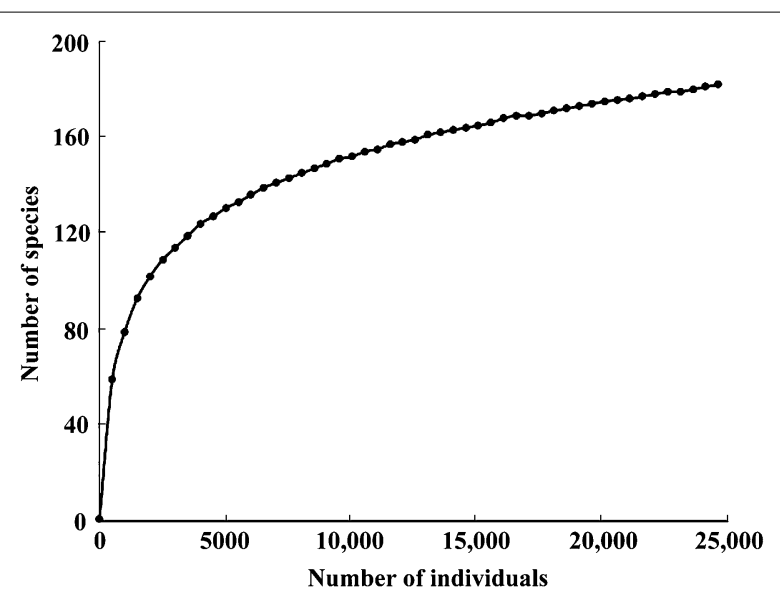

Fig. 2 Sample-based rarefaction curves. The $X$-axis has been scaled to show numbers of individuals

With respect to the six ecological types, the suborder Passeres contained the highest number of registered species, and the Natatores accounted for the largest number of counted individuals. Birds breeding in the study site were mainly comprised by species of the Oriental realm and by widespread species (Table 2; see details in Additional file 2: Table S2).

\section{Species changes before and after 2008}

Through comparisons with historical data (1958-2008), 42 bird species recorded along the shore of Dianchi Lake were new records for Kunming City. Of these, 34 species were waterbirds, including 24 shorebird species. We found that 20 species were new records for Yunnan Province; of these, 18 were waterbirds (including 15 shorebird species) (see details in Additional file 3: Table S3). This suggests that waterbirds, and particularly shorebirds, accounted for most new records for Dianchi Lake since
2008. The appendix of Wang et al. (2015) suggests that 10 waterbird species have disappeared from the shore of Dianchi Lake. These are Ciconia nigra, Platalea leucorodia, Anas formosa, Mergus albellus, Charadrius hiaticula, Larus crassirostris, L. canus, Sterna aurantia, S. caspia and Grus grus. Particularly, G. grus was once the dominant species along Dianchi Lake.

\section{Waterbird habitat preference}

Sixty-three waterbird species $(94.30 \%$ of total registered waterbird species) representing 18,913 records (99.85\% of total waterbird records) were recorded in 26 plots throughout the 24-month field investigation. All habitat variables were used to examine the relationship with the abundance of waterbirds by CCA analysis. High collinearity between habitat variables is shown in Fig. 3, except for OA, MF and WL (see Pearson correlation of habitat variables in Additional file 1: Table S1).

The results of the CCA are shown in Table 3. The eigenvalues of the first two canonical axes were much higher than those for the other two axes. All canonical axes explain $80.3 \%$ of the variance in species data and 99.8\% of the variance in species-environment relationships. The cumulative explanation of the first two axes reached $73.2 \%$ of species data and $90.9 \%$ of speciesenvironment relationship. Monte Carlo permutation tests for the first and all canonical axes were highly significant $\left(p=0.002, p_{\mathrm{Y}}=0.001\right.$, respectively). For species-environment relationships, approximately $41.5 \%$ and $29.3 \%$ of the variations were explained by axis 1 and axis 2, respectively. Overall, the first two canonical axes were able to explain quite well the relationship between species and the environmental variables. We found that seven habitat variables $(\mathrm{OA}, \mathrm{CL}, \mathrm{WF}, \mathrm{LG}, \mathrm{SB}$, WL and MF) were positively correlated with axis 1 and the remaining five were negatively correlated with axis

Table 2 Species richness and abundance

\begin{tabular}{|c|c|c|c|c|c|}
\hline Resident species & Winter visitors & \multicolumn{2}{|c|}{ Passage migrants } & Summer visitors & Vagrant visitors \\
\hline \multicolumn{6}{|c|}{ Migration status/records; species (percentages of total records; percentage of total species, \%) } \\
\hline $\begin{array}{l}5573 ; 78 \\
(22.20 ; 42.86)\end{array}$ & $\begin{array}{l}18,737 ; 41 \\
(74.66 ; 22.53)\end{array}$ & $\begin{array}{l}447 ; 3 \\
(1.78 ;\end{array}$ & & $\begin{array}{l}272 ; 16 \\
(1.08 ; 8.79)\end{array}$ & $\begin{array}{l}69 ; 8 \\
(0.27 ; 4.39)\end{array}$ \\
\hline Passeres & Grallatores & Natatores & Scansores & Raptors & Terrestores \\
\hline \multicolumn{6}{|c|}{ Ecological types/records; species } \\
\hline $\begin{array}{l}5879 ; 95 \\
(23.42 ; 52.20)\end{array}$ & $\begin{array}{l}1154 ; 45 \\
(4.60 ; 24.73)\end{array}$ & $\begin{array}{l}17,788 ; 22 \\
(70.87 ; 12.09)\end{array}$ & $\begin{array}{l}97 ; 9 \\
(0.39 ; 4.95)\end{array}$ & $\begin{array}{l}23 ; 8 \\
(0.09 ; 4.40)\end{array}$ & $\begin{array}{l}548 ; 3 \\
(0.25 ; 1.63)\end{array}$ \\
\hline \multicolumn{2}{|c|}{ Oriental realm species } & \multicolumn{2}{|c|}{ Widespread species } & \multicolumn{2}{|c|}{ Palaearctic realm species } \\
\hline \multicolumn{6}{|c|}{ Breeding bird fauna (total 58,412 records and 94 species)/records; species } \\
\hline \multicolumn{2}{|l|}{$\begin{array}{l}2601 ; 55 \\
(44.50 ; 58.51)\end{array}$} & \multicolumn{2}{|c|}{$\begin{array}{l}2425 ; 31 \\
(41.49 ; 32.98)\end{array}$} & \multicolumn{2}{|c|}{$\begin{array}{l}819 ; 8 \\
(14.01 ; 8.51)\end{array}$} \\
\hline
\end{tabular}




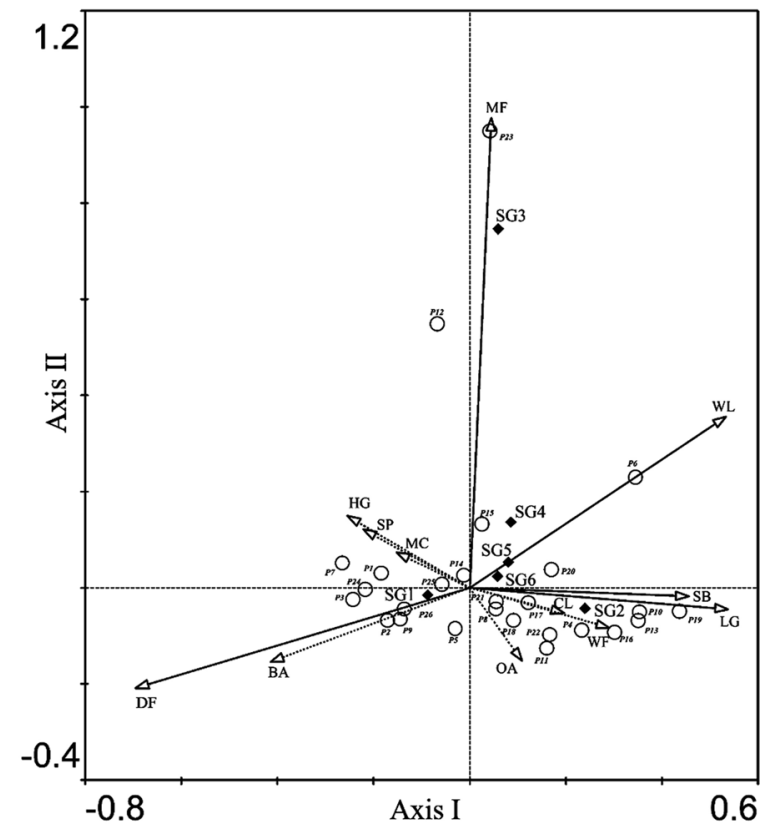

Fig. 3 CCA ordination diagram of species distribution and environmental factors in Dianchi Lake. Black arrows represented the significant affected land-cover variables $\left(p_{\mathrm{MF}}=0.025 ; p_{\mathrm{DF}}=0.006\right.$; $\left.p_{\mathrm{LG}}=0.031 ; p_{\mathrm{WL}}=0.007 ; p_{\mathrm{SB}}=0.058\right)$, while dotted arrows were the insignificant ones. Sample sits were represented by open circles, whereas species were meant by black diamonds. See abbreviation of land-cover variables in Table 1 and species code in Additional file 2: Table 52

Table 3 CCA ordination summary and correlation coefficients between habitat variables and ordination axes

\begin{tabular}{lrrrr}
\hline Summary of CCA ordination & Axis 1 & Axis 2 & Axis 3 & Axis 4 \\
\hline Eigenvalue & 0.461 & 0.268 & 0.054 & 0.018 \\
Species-environment correlations & 0.930 & 0.969 & 0.691 & 0.591 \\
Cumulative \% variance of species & 46.300 & 73.200 & 78.500 & 80.300 \\
$\quad$ data & & & & \\
Of species-environment relation & 57.500 & 90.900 & 97.600 & 99.800 \\
OA (Open water area) & 0.102 & -0.147 & 0.025 & -0.138 \\
MC (Macrophyte cover) & -0.142 & 0.071 & 0.447 & 0.238 \\
BA (Building area) & -0.386 & -0.149 & -0.174 & 0.149 \\
SP (Small pond) & -0.206 & 0.118 & -0.137 & 0.126 \\
MF (Mud flood area) & 0.042 & 0.947 & -0.081 & -0.055 \\
LG (Low grassland) & 0.501 & -0.043 & 0.031 & 0.134 \\
Dry forest cover (DF) & -0.647 & -0.202 & -0.115 & 0.099 \\
CL (Cultivated land) & 0.183 & -0.051 & -0.013 & 0.143 \\
SB (Shrub) & 0.424 & -0.018 & 0.170 & -0.189 \\
WF (Wetland forest) & 0.271 & -0.081 & 0.346 & -0.392 \\
HG (High grassland) & -0.237 & 0.145 & 0.279 & -0.337 \\
WL (Waste lands) & 0.496 & 0.345 & -0.226 & 0.097 \\
Test of significance of first canoni- & F-ration & $=11.195, p=0.002$ & \\
cal axis & & & & \\
Test of significance of all canoni- & F-ration & $-4.462, p=0.001$ & \\
cal axes & & & & \\
\hline
\end{tabular}

1. Five habitat variables (PC, SP, HG, MF and WL) and the remaining seven variables were negatively correlated with axis 2 . The bi-plot of the overall species distribution and habitat explanatory variables is shown in Fig. 3.

Forward selection of environmental variables suggested that the effects of five habitat variables (including a marginal one)-MF, DF, LG, WL and SB$(p=0.058)$ significantly $(p<0.05)$ affected waterbird distribution (Fig. 3). Partial CCA suggested that, of the five main habitat variables, MF alone accounted for $40 \%\left(p_{\mathrm{Y}}=0.001\right)$ of the variation in the bird data, and DF solely explained $40.1 \%\left(p_{Y}=0.01\right)$ of the variation. LG, WL and SB did not reach a significant level.

The statistical significance of each species' response to the five major environmental variables was tested by producing $t$-value bi-plots based on the CCA procedure. The relationship between single species and a particular environmental variable is shown in Fig. 4. DF had a significant positive correlation with gulls (SG1) and a significant negative correlation with wintering coots and ducks (SG2) (Fig. 4a). SG2 were significantly positively related with WL, while SG1 were significantly negatively correlated with WL (Fig. 4b). Shorebirds (SG3) were significantly positively correlated with MF (Fig. 4c) while other habitat variables showed little relevance to this sub-group. Overall, SG4, SG5 and SG6 showed similar responses, and presented similar correlation trends to the habitat variables, but none was statistically significantly affected. SG1 responses to habitat variables were opposite those of SG4/SG5/SG6 except for response to MF (Fig. 4a-e).

\section{Discussion}

In our two-year survey, 182 species belonging to 49 families and 15 orders of birds were detected, suggesting that Dianchi Lake could provide a suitable habitat for wild birds and not just for waterbirds. Species of different migration status, ecological types and breeding fauna of bird species and individuals recorded here suggest that Dianchi Lake is an important wild bird breeding, stopover and wintering site (Table 2). This implies that lake restoration management should take into account the requirements of different wild birds, and especially waterbirds (breeders, migrants and winter visitors).

Species responses to wetland restoration in urbanized area We found many new bird records for Kunming City and Yunnan Province during our fieldwork and in the observations of others (see details in Additional file 3: Table S3). This suggests that more frequent bird surveys (that is, greater sampling effort) could lead to additional 

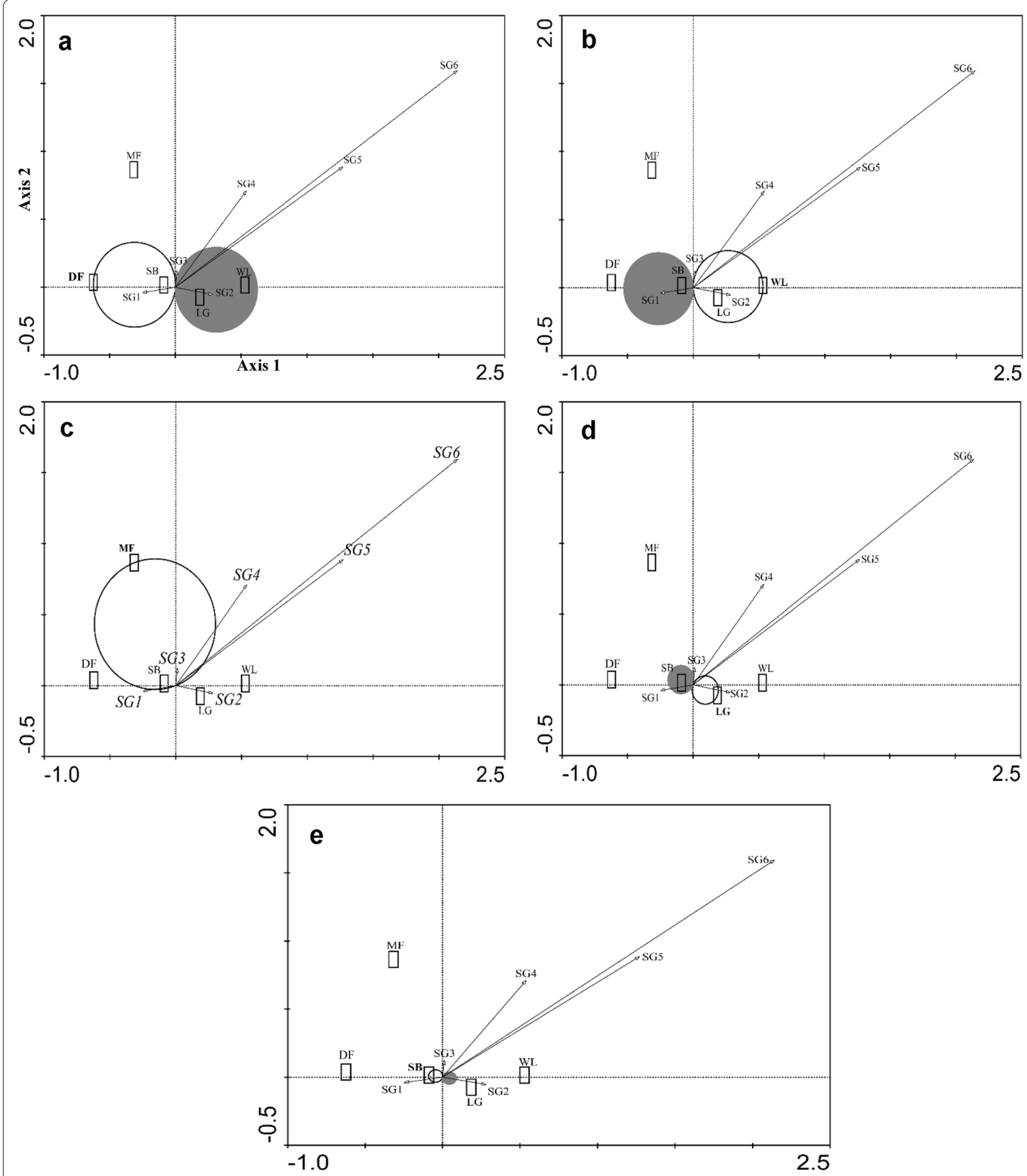

Fig. $4 t$-value biplots of the five main environmental variables. a DF, b WL, c MF, d LG and e SB. The arrows indicated each sub species groups, and empty boxes represented environmental variables. The circles filled with gray color represented negative correlation while the transparent ones represented positive correlation 
new bird records (Liu et al. 2013). Most of the new records are of waterbirds (34 of all $42 \mathrm{NKB}$ and 18 of all $20 \mathrm{NYB}$ ), and this may indicate that wetland restoration projects in urban settings benefit birds, and especially waterbirds (Mander et al. 2007; McKinney et al. 2011). We also found that numerous new bird records were of shorebirds (24 NKB and 15 NYB). Most of these species were recorded in mud-flooded wetlands, showing the high dependence on this habitat by shorebirds (Murray and Fuller 2015). In addition, more than eight studies reported shorebirds among the new bird records for Yunnan Province (Luo 2014). The use of inland mudflooded wetlands by shorebirds may also be a result of coastal wetland degradation, driving some of them to seek new habitats in inland areas (Ma et al. 2002). If mud-flooded habitats were to form during migration seasons in western or central China, we believe that more (new) shorebird species would be found in these regions by more researchers and birdwatchers.

Although there is no reliable and representative bird checklist of Dianchi Lake before 2008, we still found the ten of the most historically recorded waterbird species are now absent from Dianchi Lake. Little information was available on the absent species, but the Common Crane (G. grus) - a dominant wintering visitor around Dianchi Lake in the 1960s (Kuang 1960)-is today absent from the lake (Wang et al. 2015). Conspicuous and rapid increases in numbers of wintering Blackheaded Gulls were apparent, from about 3000-30,000 individuals during 1985-2000 (Wang et al. 2006). One reason for this may be related to the growing tourism activity of feeding them in Kunming City parks (Guan et al. 2008). We suggest that the intensified urbanization and reclamation of the last few decades (Tan et al. 2010) has driven away sensitive species, while synanthropic species have increased rapidly (Blair 1996; Maciusik et al. 2010; Donaldson et al. 2016). An alternative reason for species disappearance may be that the historical records were of vagrant visitors or rare species in Dianchi Lake. During re-checking of specimens in 2005, a specimen collected in 1981 was confirmed to be a Caspian Tern (Sterna caspia). As this was the first record of this species in Yunnan (Yang 2005), it suggests that it was a rare species or vagrant visitor to Dianchi Lake in 1981.

\section{Waterbird habitat preference}

The relationships between the distribution of most waterbirds and habitat characteristics, as revealed by CCA, were in agreement with the birds' ecological requirements. For instance, the shorebirds (SG3) concentrated significantly in the mudflat (MF) wetlands (Bellio and Kingsford 2013; Aarif et al. 2014; Clemens et al. 2014;
Murray and Fuller 2015). The wintering ducks and coots (SG2) clearly preferred the water area next to the waste lands cover (WL) and avoided dry forest cover (DF) (Paracuellos 2006; Cardoni et al. 2008; Ma et al. 2010). Along Dianchi Lake, trees have always been planted in the relatively well-managed parks for their scenic value, attracting many visitors who toss large quantities of food to gulls during the winter season (unpublished observation). The higher DF along Dianchi Lake usually suggested more human recreation activities. The habitat preference of gulls (SG1) was the complete opposite of SG2, which significantly avoided the WL and concentrated in DF (Andersson et al. 1981; Guan et al. 2008; Liordos 2010; Maciusik et al. 2010). The distributions of egrets (SG4), breeding rails (SG5) and grebes (SG6) were negatively correlated with DF and shrub cover (SB), while positively correlating with other variables, but none of these relationships was statistically significant. This situation seemed to reflect wider habitat use by resident species, which can move among patches during different seasons, searching for suitable resources, and which are more tolerant of variation in the local habitats (Chen et al. 2000; Rendón et al. 2008; Donaldson et al. 2016).

The partial CCA also indicated that DF and MF were the only two independent explanatory variables that can significantly explain the variation in the bird data alone, $40.1 \%$ and $40 \%$, respectively, in our study. This may suggest the vulnerability of the bird community along Dianchi Lake, because these two variables are highly dependent on human activities. The wintering gulls concentrated significantly on DF, which means they foraged in the well-managed parks, depending on the food supply from tourists (Wu et al. 2008). The concentration of gulls increases their vulnerability to disease, reduces their wariness of people and favors their domestication (Ma et al. 2009). After avian influenza broke out in China in the early 2000s, tourists did not dare to feed the gulls, and numbers of gulls foraging in urban parks reduced by 9000 (Kunming Bird Association 2006). Most shorebirds were counted in the mudflat wetlands formed temporarily by construction-work yards. Once the construction is finished the mudflat wetlands also disappear. In the biggest mudflat wetlands with the highest shorebird numbers of our sampling sites, many fewer shorebirds were encountered after construction stopped in 2014, as the area became bare ground without any water $(\mathrm{H}$. Bai, personal communication 2015). No significant correlations between most variables and species were found in our study. This does not imply, however, that those variables were of no importance in determining species community composition. We can only conclude that the correlation did not reach a significant level in this study. Hence, 
further work is needed to determine the effects of the variables.

\section{Management implications}

Wetland restoration projects can benefit wetland birds (Mander et al. 2007; Murray et al. 2013). Studies on managed realignment sites in the UK have shown that birds colonize and adapt quickly to new habitats (Mander et al. 2007). We suggest that, as the food resource of wintering gulls in our study is largely dependent on humans, food is provided appropriately to keep them wild and that attention is paid to avian influenza (Poland et al. 2007; Wu et al. 2008) and potential water contamination (Jones and Reynolds 2008). Several more well-managed parks should be included along the suburban lakeshore to dilute the high density of foraging gulls in the urban area (Maciusik et al. 2010). The use of food-supply platforms for gulls should be considered when designing the parks, rather than depending on volunteers to throw food for them during sensitive periods, such as during outbreaks of avian influenza. Our results testified that a certain number of shorebirds also use available habitats in inland China, although most of them were encountered in the mudflat wetlands formed temporarily by constructionwork yards. These habitats disappear when the construction projects finish, resulting in a decrease in shorebird diversity (Ma et al. 2014). We strongly recommend that mudflat habitats be designed and managed for migrating shorebirds on the lakeshore to allow a more comprehensive restoration of Dianchi wetland ecosystem functions (Francesco et al. 2013; Clemens et al. 2014; Murray and Fuller 2015; Wang et al. 2016). In our study, wintering coots and ducks usually appeared in large numbers in the water area next to WL, suggesting a lower human presence there (Paracuellos 2006; Cardoni et al. 2008; Ma et al. 2010). This indicated to us that, when the wetlands for the entire lakeshore are designed, a certain degree of semi-natural habitat with low or no human recreation access must be reserved for these species (Cardoni et al. 2008; Ma et al. 2010). The recording of mostly resident species of waterbird in all 26 sites may be explained by the long history of adaptation to local fragmentation and disturbance (Rendón et al. 2008; Donaldson et al. 2016). Nevertheless, dense aquatic plants, excess MC and human disturbance have had a negative effect on their habitat use (Cardoni et al. 2008; Ma et al. 2010 and our observation). Incorporating appropriate plant density and a buffer zone (lowering human disturbance) should be taken into consideration when implementing restoration, to meet the habitat utilization requirements of resident waterbirds.

\section{Conclusions}

In summary, the presence of numerous migratory and resident birds recorded in our study shows that Dianchi Lake is an important habitat for wild birds, which could use it as a breeding, stopover and wintering site. We suggest that intensified urbanization and reclamation during the last few decades has driven away sensitive species, while synanthropic species have increased rapidly. Wetland restoration projects have benefited many bird species, especially waterbirds. Distribution of different waterbird species is highly dependent on human activities. Different types of restoration management should be implemented, to take into account the varied habitat requirements of different waterbird groups, and allow a more comprehensive restoration of Dianchi Lake wetland ecosystem functions.

\section{Additional files}

Additional file 1: Table S1. Percentages of different land-covers of the 26 sampling sites around Dian Lake and the Pearson correlation of the land-cover variables.

Additional file 2: Table S2. Bird checklist of Dianchi Lake.

Additional file 3: Table S3. New bird records found along Dianchi Lake during 2008-2016.

\section{Acknowledgements}

We thank Doyle McKey from Université de Montpellier, Bo Wang from Xishuangbanna Tropical Botanical Garden, Christos Mammides from Guangxi University and Donglai Li from Liaoning University for their generous help in language editing and insightful comments about the manuscript. We thank senior schoolmates Jianyun Gao and Dongdong Su for their enormous help in this study during the pre-surveys, PhD senior schoolmate Longyuan He for his kind help in mapping, Prof. Zhiming Zhang for his great help in the data analyses, faculty of the Kunming Bird Association for their help in the field investigation and memberships in the QQ groups of Students union of Birdwatching, and Yunnan Wild Bird Association and Young Ornithologists for their help in identifying some species.

\section{Authors' contributions}

$\mathrm{KL}$ and $\mathrm{Z}$. Wu designed the experiments. $\mathrm{KL}$ and $\mathrm{HB}$ implemented the field surveys and collected the data. $K L$ finished the data analysis and wrote the first draft. KL, Z. Wu and Z. Wang supervised the research and provided multiple revisions in the early stages of writing. All authors read and approved the final manuscript.

\section{Funding}

The National Natural Science Foundation of China (41471149 and 31060079) financially supported this study.

\section{Availability of data and materials}

The datasets used in the present study are available from the corresponding author on reasonable request.

Ethics approval and consent to participate

The experiments comply with the current laws of China.

Consent for publication

Not applicable. 


\section{Competing interests}

The authors declare that they have no competing interests.

\section{Author details}

${ }^{1}$ CAS Key Laboratory of Tropical Forest Ecology, Xishuangbanna Tropical Botanical Garden, Chinese Academy of Sciences, Xishuangbanna 666303, Yunnan, China. ${ }^{2}$ Institute of Ecology and Geobotany, Yunnan University, Kunming 650091, China. ${ }^{3}$ Center for Integrative Conservation, Xishuangbanna Tropical Botanical Garden, Chinese Academy of Sciences, Xishuangbanna 666303, Yunnan, China. ${ }^{4}$ University of Chinese Academy of Sciences, Beijing 100049, China.

Received: 19 September 2018 Accepted: 31 May 2019

Published online: 06 June 2019

\section{References}

Aarif MK, Muzaffar SB, Babu S, Prasadan KP. Shorebird assemblages respond to anthropogenic stress by altering habitat use in a wetland in India. Biodivers Conserv. 2014;23:727-40.

An SQ, Li HB, Guan BH, Zhou CF, Wang ZS, Deng ZF, Zhi YB, Liu YH, Xu C, Fang SB, Jiang JH, Li LH. China's natural wetlands: past problems, current status, and future challenges. Ambio. 2007;36:335-42.

Andersson M, Götmark F, Wiklund CG. Food information in the Black-Headed Gull, Chroicocephalus ridibundus. Behav Ecol Sociobiol. 1981;9:199-202.

Asomani-Boateng R. Urban wetland planning and management in Ghana: a disappointing implementation. Wetlands. 2019;39:251-61.

Bellio MG, Kingsford RT. Alteration of wetland hydrology in coastal lagoons: implications for shorebird conservation and wetland restoration at a Ramsar site in Sri Lanka. Biol Conserv. 2013;167:57-68.

Bibby CJ, Burguess ND, Hill DA, Mustoe S. Bird census techniques. 2nd ed. New York: Academic Press; 2000.

Blair RB. Land use and avian species diversity along an urban gradient. Ecol Appl. 1996:6(2):506-19.

Cao L, Fox AD. Birds and people both depend on China's wetlands. Nature. 2009:460:173.

Cardoni DA, Favero M, Isacch JP. Recreational activities affecting the habitat use by birds in Pampa's wetlands, Argentina: implications for waterbirds conservation. Biol Conserv. 2008;141:797-806.

Chen KL. Wetlands and waterbirds of China. Bull Biol. 1998;33:2-4.

Chen SH, Ding P, Zheng GM, Zhu GY. Impacts of urbanization on the wetland waterbirds communities in Hangzhou. Zool Res. 2000;21(4):279-85 (in Chinese).

Clemens RS, Herrod A, Weston MA. Lines in the mud: revisiting the boundaries of important shorebird areas. J Nat Conserv. 2014;22:59-67.

Cui P, Wu Y, Ding H, Wu J, Cao MC, Chen L, Chen B. Status of wintering waterbirds at selected locations in China. Waterbirds. 2014;37:402-9.

Donaldson L, Woodhead AJ, Wilson RJ, Maclean IMD. Subsistence use of papyrus is compatible with wetland bird conservation. Biol Conserv. 2016:201:414-22.

Ehrenfeld JE. Evaluating wetlands within an urban context. Ecol Eng. 2000;15:253-65.

Francesco S, Giovanni C, Claudia C, Roberto V. The importance of dredge islands for breeding waterbirds. A three-year study in the Venice Lagoon (Italy). Ecol Eng. 2013;54:39-48.

Gill F, Donsker D. IOC World Bird List (v 4.4). 2014. https://doi.org/10.14344/IOC. ML.4.4.

Gotelli NJ, Entsminger GL. EcoSim: null models software for ecology. Version 7. Jericho: Acquired Intelligence Inc. \& Kesey-Bear; 2006.

Guan XX, Zhao XB, Wu ZL. Effects of Black-headed gull to tourist number at two tourism sites in Kunming. Yunnan Geogr Environ Res. 2008;20(6):85-9 (In Chinese)

Han LX, Li F, Zhao JL, Wu ZR, Yu HZ, Luo X, Huang SL. The bird diversity of Napa Lake Nature Reserve. In: Wang ZJ, Huang HK, Yang XJ, editors. Birds protecting and harmony with human. Beijing: China Forestry Publishing House; 2009. p. 78-86 (in Chinese).

Han LX, Deng ZW, Lu HL, Li JJ, Cheng C, Han B. Morphological comparison between the naturally and artificially fed Black-headed gulls during wintering period. J Southwest For Univ. 2012;32(3):104-6 (in Chinese).
Han LX, Deng ZW, Yan D. Bird diversity in shore habitats of Erhai Lake, Yunnan Province. Chin J Zool. 2014;49:185-94 (in Chinese).

Hu SY, Ran JH, Dou L, Cai G, Zheng ZR, Li B. Survey on winter waterfowls in the east and southwest of Sichuan province. Sichuan J Zool. 2015;34:120-5 (in Chinese)

Hua YY, Cui BS, He WJ. Changes in water birds habitat suitability following wetland restoration in the Yellow River Delta, China. Clean-Soil Air Water. 2012;40(10):1076-84.

Jones DN, Reynolds JS. Feeding birds in our towns and cities a global research opportunity. Avian Biol. 2008;39(3):265-71.

Kuang BY. Preliminary observation on the wintering characteristics of Anser fabalis serirostris. Chin J Zool. 1960;6:253-4 (in Chinese).

Lepš J, Šmilauer P. Multivariate analysis of ecological data using CANOCO. Cambridge: Cambridge University Press; 2003. p. 124-39.

Li QP, Sun Y. Number of wintering cranes and waterbirds at the Bitahai nature reserve, Yunnan, China in 2013. Zool Res. 2014;35:243-5 (in Chinese).

Li LX, Yang GJ. Analysis and investigation on wintering waterfowl of Yunnan Lugu Lake. For Invent Plan. 2015:40:74-8 (in Chinese).

Li DL, Chen SH, Guan L, Lloyd H, Liu XL, Lv JZ, Zhang ZZ. Patterns of waterbird community composition across a natural and restored wetland landscape mosaic, Yellow River Delta, China. Estuar Coast Shelf Sci. 2011;91:325-32.

Liordos V. Foraging guilds of waterbirds wintering in a Mediterranean coastal wetland. Zool Stud. 2010;49(3):311-23.

Liu W, Qiu RL. Water eutrophication in China and the combating strategies. J Chem Technol Biot. 2007;82:781-6.

Liu Y, Wei S, Dong L, Lei JY. On an update of recent new bird records in China. Chin J Zool. 2013;48(5):750-8 (in Chinese).

Luo K. Communities and habitat selection of wetland birds in the lakeshorewetland around the Dianchi Lake. Master's Thesis. Yunnan: Yunnan University; 2014 (in Chinese).

Ma G, Wang S. Temporal and spatial distribution changing characteristics of exogenous pollution load into Dianchi Lake, Southwest of China. Environ Earth Sci. 2015;74(5):3781-93.

Ma ZJ, Tang SM, Lu F, Chen JK. Chongming Island: a less important shorebird stopover site during southward migration? Stilt. 2002;41:35-7.

Ma ZJ, Li B, Li WJ, Han NY, Chen JK, Watkinson AR. Conflicts between biodiversity conservation and development in a biosphere reserve. J Appl Ecol. 2009;46:527-35.

Ma ZJ, Cai YT, Li B, Chen JK. Managing wetland habitats for waterbirds: an international perspective. Wetlands. 2010;30:15-27.

Ma ZJ, Melville DS, Liu JG, Chen Y, Yang HY, Ren WW, Piersma T, Li B. Rethinking China's new great wall. Science. 2014;346(6212):912-4.

Maciusik B, Lenda M, Skórka P. Corridors, local food resources, and climatic conditions affect the utilization of the urban environment by the Black-headed Gull Chroicocephalus ridibundus in winter. Ecol Res. 2010:25:263-72.

MacKinnon J, Philipps K, He FQ. A field guide to the birds of China. Changsha: Hunan Education Press; 2000.

Mander L, Cutts ND, Allen J, Mazik K. Assessing the development of newly created habitat for wintering estuarine birds. Estuar Coast Shelf Sci. 2007;75:163-74.

Mao XF, Wei XY, Jin X, Tao YQ, Zhang ZF, Wang WY. Monitoring urban wetlands restoration in Qinghai Plateau: integrated performance from ecological characters, ecological processes to ecosystem services. Ecol Indic. 2019;101:623-31.

McKinney RA, Raposa KB, Cournoyer RM. Wetlands as habitat in urbanizing landscapes: patterns of bird abundance and occupancy. Landsc Urban Plan. 2011;100:144-52.

Mitsch W, Gosselink J. Wetlands. New York: Willey; 2007

Murray NJ, Fuller RA. Protecting stopover habitat for migratory shorebirds in East Asia. J Ornithol. 2015;156:217-25.

Murray CG, Kasel S, Loyn RH, Hepworth G, Hamilton AJ. Waterbirds' use of artificial wetlands in an Australian urban landscape. Hydrobiologia. 2013;716:131-46

Nakamura K, Tockner K, Amano K. River and wetland restoration: lessons from Japan. Bioscience. 2006;56:419-29.

Ntongani WA, Andrew SM. Bird species composition and diversity in habitats with different disturbance histories at Kilombero Wetland, Tanzania. Open J Ecol. 2013;3:482-8. 
Paracuellos M. How can habitat selection affect the use of a wetland complex by waterbirds? Biodivers Conserv. 2006;15:4569-82

Pethick J. Estuarine and tidal wetland restoration in the United Kingdom: policy versus practice. Restor Ecol. 2002;10:431-7.

Poland GA, Jacobson RM, Targonski PV. Avian and pandemic influenza: an overview. Vaccine. 2007;25(16):3057-61.

Quan RC, Wen XJ, Yang XJ. Numbers of migratory waterbirds at Lake Lashihai, China. Waterbirds. 2002;25:239-43.

Rendón MA, Greena AJ, Aguilera E, Almaraz P. Status, distribution and longterm changes in the waterbirds community wintering in Doñana, southwest Spain. Biol Conserv. 2008;141:1371-88.

Russi D, ten Brink P, Farmer A, Badura T, Coates D, Förster J, Kumar R, Davidson $\mathrm{N}$. The economics of ecosystems and biodiversity for water and wetlands. London/Brussels/Gland: IEEP/Ramsar Secretariat; 2013.

Sievers M, Hale R, Parris KM, Swearer SE. Impacts of human-induced environmental change in wetlands on aquatic animals. Biol Rev. 2018;93:529-54.

Tan ZW, Zhu X, Che Y. Dynamic changes of lakeside landscape pattern of Dianchi Lake basin in recent sixty years. Environ Sci Surv. 2010;29(5):40-5 (in Chinese)

Terörde Al, Turpie JK. Influence of habitat structure and mouth dynamics on avifauna of intermittentlyopen estuaries: a study of four small South African estuaries. Estuar Coast Shelf Sci. 2013;125:10-9.

Wang SM, Dou HS. Lakes of China. Beijing: Science Press; 1998.

Wang ZJ, Huang HK, Wu JL, Yang M. Variation of individuals and distribution of wintering Black-headed gulls in Kunming based on 20 years' monitoring. In: Wang YC, Wang ZJ, Gao ZW, Yang L, editors. China (Kunming) International Forum on Human and Birds live in harmony. Kunming: Yunnan Science and Technology Press; 2006. p. 244-5 (in Chinese)

Wang ZJ, Zhao XB, Luo K. Avian changes in fifty years (1963-2013) in Kunming, China. Sichuan J Zool. 2015;34(4):599-613 (in Chinese).

Wang RX, Wu F, Chang YY, Yang XJ. Waterbirds and their habitat utilization of artificial wetlands at Dianchi Lake: implication for waterbirds conservation in Yunnan-Guizhou Plateau Lakes. Wetlands. 2016;36(6):1087-95.

Wang XD, Kuang FL, Tan K, Ma ZJ. Population trends, threats, and conservation recommendations for waterbirds in China. Avian Res. 2018;9:14.

Wei P, Zan QJ, Tam NFY, Shin PKS, Cheung SG, Li MG. Impact of habitat management on waterbirds in a degraded coastal wetland. Mar Pollut Bull. 2018;124:645-52.
Wu ZL, Zheng ML, Pan BZ, Zhao XB, Wang ZJ, Yang M. Duration and its influencing factors of wintering Black-headed Gull in Kunming City zone. Sichuan J Zool. 2008;27(3):351-5 (in Chinese)

Wu ZL, Zhao XB, Wang ZJ, Yang M. The wildness loss of wintering Blackheaded gull caused by human feeding and urban wild bird management in Kunming. Yunnan Geogr Environ Res. 2009;21(5):1-4 (in Chinese).

Xiang XX. A study on higher plants and their communities in wetlands around Dianchi Lake. Master's Thesis. Yunnan: Yunnan University; 2014 (in Chinese)

Xu HG, Wang SQ, Xue DY. Biodiversity conservation in China: legislation, plans and measures. Biodivers Conserv. 1999;8:819-37.

Yang L. A new record of the Caspian Tern (Sterna caspia) in Dianchi Lake of Yunnan, China. Zool Res. 2005:6:602 (in Chinese).

Yang L, Yang XJ. The avifauna of Yunnan, China. Kunming: Yunnan Science and Technology Press; 2004.

Yang L, Li H, Yang XJ. Wetlands of Yunnan. Beijing: China Forestry Publishing House; 2010 (in Chinese)

Yuan YJ, Zeng GM, Liang J, Li XD, Li ZW, Zhang C, Huang L, Lai X, Lu LH, Wu $H P, Y u X$. Effects of landscape structure, habitat and human disturbance on birds: a case study in East Dongting Lake wetland. Ecol Eng. 2014;67:67-75.

Zedler JB. Progress in wetland restoration ecology. Trends Ecol Evol. 2000;15(10):402-7.

Zedler JB, Kercher S. Wetland resources: status, trends, ecosystem services, and restorability. Annu Rev Env Resour. 2005;30:39-74.

Zedler JB, Leach MK. Managing urban wetlands for multiple use: research, restoration and recreation. Urban Ecosyst. 1998;2:189-204.

Zhang WW, Liu W, Ma JZ. Territory and territorial behavior of migrating Common Coot (Fulica atra). J For Res. 2011;22(2):289-94.

Zhao ZJ. A handbook of the birds of China. Jilin: Jilin Science and Technology Press; 2001 (in Chinese).

Zheng GM. Ornithology. Beijing: Beijing Normal University Press; 2012 (in Chinese).
Ready to submit your research? Choose BMC and benefit from:

- fast, convenient online submission

- thorough peer review by experienced researchers in your field

- rapid publication on acceptance

- support for research data, including large and complex data types

- gold Open Access which fosters wider collaboration and increased citations

- maximum visibility for your research: over $100 \mathrm{M}$ website views per year

At BMC, research is always in progress.

Learn more biomedcentral.com/submissions 